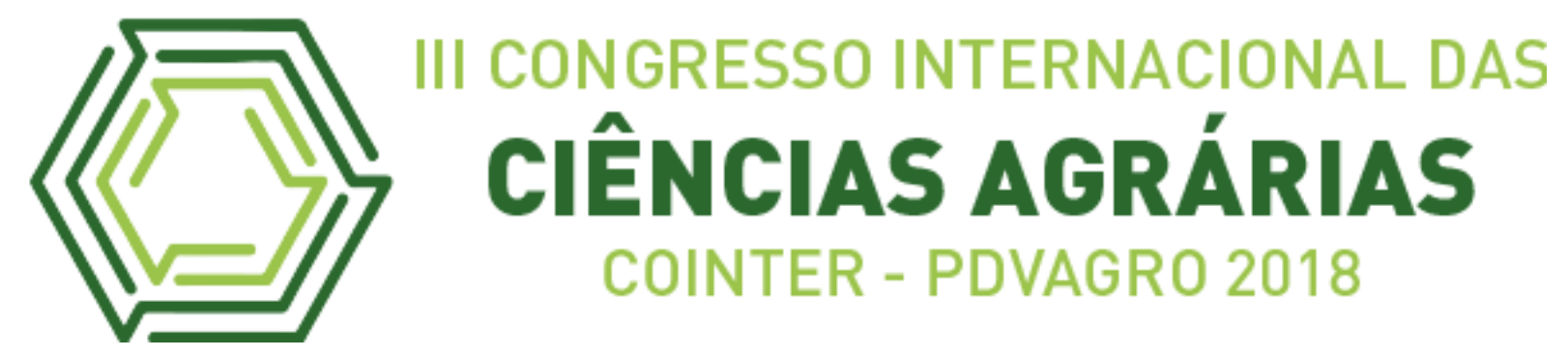

\title{
SABERES AMAZÔNICOS: ESTUDO ETNOBOTÂNICO DE UMA ALDEIA INDÍGENA NO SUDESTE DO PARÁ
}

\section{AMAZON KNOWLEDGE: ETHNOBOTANICAL STUDY OF AN INDIGENOUS VILLAGE IN SOUTH EAST PARÁ}

\author{
Apresentação: Pôster \\ Thayrine Silva Matos ${ }^{1}$; Marcelo Mendes Braga Junior ${ }^{2}$; Gabriele Melo de Andrade ${ }^{3}$; \\ Maria Rita Lima Calandrini Azevedo ${ }^{4}$; Camila Tamires Arrais Furtado ${ }^{5}$ \\ DOI: https://doi.org/10.31692/2526-7701.IIICOINTERPDVAGRO.2018.00658
}

\section{Introdução}

Os produtos naturais são utilizados pela humanidade desde tempos imemoriais. A busca por alívio e cura de doenças pela ingestão de ervas e/ou folhas talvez tenham sido uma das primeiras formas de utilização dos produtos naturais (VIEGAS JÚNIOR et al., 2005). O Brasil detém a maior biodiversidade do planeta, em torno de 15 a $20 \%$ do total. Possui também um valioso conhecimento tradicional relacionado ao uso de plantas medicinais, devido à diversidade étnica e cultural (BRASIL, 2006). Pesquisas recentes demonstram que mais de 90\% da população já fez uso de alguma planta medicinal (ABIFISA, 2017).

Cardoso et al. (2017) registrou para bacia amazônica a existência de 14.003 espécies de plantas espermatófitas, distribuídas em 1.788 gêneros e 188 famílias botânicas. Diante da vasta biodiversidade da Amazônia, pouco se conhece sobre as espécies com potencial medicinal, exceto os que detêm a sabedoria e conhecimento empírico, aqueles chamados de pajés, xamãs, curandeiros, feiticeiros, benzedeiras, rezadeiras, que consideram as plantas como seres sensíveis e sensitivos (BORRÁS, 2003).

Muitos autores defendem que as plantas medicinais são aquelas reconhecidas pela população como uma espécie que tem valor medicinal, ou seja, que tem alguma propriedade

\footnotetext{
${ }^{1}$ Graduando em Engenharia Florestal, Universidade do Estado do Pará, thayrine.matos@gmail.com

${ }^{2}$ Graduando em Engenharia Florestal, Universidade do Estado do Pará, bragajuniorm@gmail.com

${ }^{3}$ Graduando em Engenharia Florestal, Universidade do Estado do Pará, andradegm@outlook.com

${ }^{4}$ Graduando em Engenharia Florestal, Universidade do Estado do Pará, mritacalandrini@gmail.com

${ }^{5}$ Graduada em Ciências Naturais - Química, Secretaria de Educação do Estado, camila-tamise@hotmail.com
} 
que serve para prevenir ou combater determinadas doenças (NOLLA et al, 2005; DI STASI, 2007).

O conhecimento do arsenal químico da natureza, pelos povos indígenas pode ser considerado fator fundamental para descobrimento de medicamentos fitoterápicos ao longo do tempo (VIEGAS JÚNIOR, 2006). É necessário ressaltar que em muitas localidades o uso dessas ervas medicinais é a única alternativa terapêutica de combate as doenças. (BADKE, 2008)

Tendo em vista a importância da documentação de informações sobre a utilização de plantas medicinais utilizadas por indígenas, o objetivo desse trabalho é realizar a identificação das espécies florestais utilizadas em uma aldeia no Sudeste do Pará, bem como a indicação terapêutica e os métodos de preparo.

\section{Fundamentação Teórica}

Plantas medicinais tem base na tradição e tornou-se prática generalizada na medicina popular. Atualmente, muitos fatores têm contribuído para o aumento da utilização deste recurso, entre eles, o alto custo dos medicamentos industrializados, o difícil acesso da população à assistência médica, bem como a tendência, nos dias atuais, ao uso de produtos de origem natural (SIMÕES et al.,1998; BRASILEIRO et al., 2008).

A diversidade cultural indígena é reconhecida pelo potencial imenso de conhecimento e experiências, se caracteriza hoje como fonte de riqueza e alvo de espoliação. Ou seja, o objeto de apropriação não se restringe somente aos recursos hídricos, minerais e vegetais de suas terras, atingindo os conhecimentos tradicionais associados à biodiversidade (CASTRO, 2007).

\section{Metodologia}

A Aldeia utilizada como objeto da pesquisa está localizada entre os municípios de Marabá, São Domingos do Araguaia e São Geraldo do Araguaia, tem uma área de 26,257 hectares no sudeste do Pará, homologada e registrada no CRI e SPU (SIASI/SESAI, 2010). O trabalho foi exploratório descritivo, com abordagem quanti-qualitativa. Para o levantamento de informações foram realizadas entrevistas semi-estruturadas com os moradores da aldeia. A partir das entrevistas foram obtidas informações sobre: nome popular, material botânico utilizado, modo de preparo, indicações terapêuticas. 
A partir do levantamento das espécies florestais utilizadas pelos indígenas para preparo de fitoterápicos, foi realizado a coleta e a partir das mesmas foram preparadas exsicatas e posteriormente enviadas ao Herbário IAN, vinculado ao laboratório de botânica da EMBRAPA Amazônia oriental, onde foi realizada a identificação botânica.

\section{Resultados e Discussões}

É notável a importância do uso de plantas medicinais para a comunidade indígena. $\mathrm{O}$ levantamento etnobotânico resultou em uma listagem de nove espécies florestais pertencentes à quatro famílias botânicas diferentes, a ausência de órgão reprodutivo no momento da coleta não permitiu a identificação de algumas espécies utilizadas.

A variedade das espécies de plantas citadas pelos entrevistados, com seu nome vulgar e científico, suas respectivas famílias botânicas, a forma em que são consumidas e suas possíveis propriedades terapêuticas estão representadas na Tabela 1.

Tabela 1: Lista de espécies medicinais utilizadas pela comunidade indígena. Fonte: Própria.

\begin{tabular}{|c|c|c|c|c|c|}
\hline $\begin{array}{c}\text { Nome } \\
\text { popular }\end{array}$ & $\begin{array}{l}\text { Nome } \\
\text { científico }\end{array}$ & $\begin{array}{l}\text { Família } \\
\text { Botânica }\end{array}$ & $\begin{array}{l}\text { Material } \\
\text { Botânico } \\
\text { Utilizado } \\
\end{array}$ & $\begin{array}{l}\text { Indicação } \\
\text { terapêutica }\end{array}$ & $\begin{array}{l}\text { Modo de } \\
\text { preparo }\end{array}$ \\
\hline Mogno & $\begin{array}{c}\text { Swietenia } \\
\text { macrophylla } \\
\text { King. }\end{array}$ & Meliaceae & Casca & $\begin{array}{l}\text { "Para a doença } \\
\text { ir embora" }\end{array}$ & Banho \\
\hline Jatobá & $\begin{array}{c}\text { Hymeneae } \\
\text { courbaril L. }\end{array}$ & Fabaceae & Casca & Diabete & Chá \\
\hline Embaúba & $\begin{array}{c}\text { Cecropia } \\
\text { pachystachya } \\
\text { Miq. }\end{array}$ & Urticaceae & Seiva & Próstata/ rins & $\begin{array}{l}\text { Água da } \\
\text { planta }\end{array}$ \\
\hline Sapucaia & $\begin{array}{l}\text { Lecythis pisonis } \\
\text { Cambess. }\end{array}$ & Lecythidaceae & Folha & Coceira & Banho \\
\hline Castanha & $\begin{array}{c}\text { Bertholletia } \\
\text { excelsa Bonpl. }\end{array}$ & Lecythidaceae & $\begin{array}{c}\text { Casca } \\
\text { Semente }\end{array}$ & $\begin{array}{c}\text { Coceira } \\
\text { Dor de dente }\end{array}$ & $\begin{array}{c}\text { Banho } \\
\text { Queimado }\end{array}$ \\
\hline Copaíba & $\begin{array}{l}\text { Copaifera } \\
\text { langsdorfii } \\
\text { Desf. }\end{array}$ & Fabaceae & Óleo & Dor de ouvido & Óleo \\
\hline Cumaru & $\begin{array}{c}\text { Dipteryx } \\
\text { odorata (Aubl.) } \\
\text { Willd. }\end{array}$ & Fabaceae & Semente & Gripe & $\begin{array}{l}\text { Macerado } \\
\text { com leite }\end{array}$ \\
\hline $\begin{array}{l}\text { Cipó de } \\
\text { fogo / } \\
\text { escadinha }\end{array}$ & $\begin{array}{c}\text { Não } \\
\text { Identificada }\end{array}$ & & Cipó & $\begin{array}{l}\text { Dor de barriga/ } \\
\text { febre/ dor de } \\
\text { cabeça }\end{array}$ & $\begin{array}{l}\text { Água da } \\
\text { planta }\end{array}$ \\
\hline
\end{tabular}




\begin{tabular}{|c|c|c|c|c|}
\hline $\begin{array}{l}\text { Pau do } \\
\text { Índio }\end{array}$ & $\begin{array}{c}\text { Não } \\
\text { identificada }\end{array}$ & Casca & Dor de cabeça & $\begin{array}{c}\text { Extrato } \\
\text { hidro- } \\
\text { alcoólico }\end{array}$ \\
\hline
\end{tabular}

A família mais representativa foi a Fabaceae (3 spp.), seguida da Lecythidaceae, estas são amplamente distribuídas (JUDD et al., 2009), e frequentemente usadas com objetivo medicinal por comunidades amazônicas (COELHO-FERREIRA, 2009; RODRIGUES, 2006; VÁSQUEZ et al., 2014).

As espécies florestais utilizadas com objetivo medicinal foram indicadas para oito diferentes sintomas que representam os principais enfrentados pela comunidade indígena. Sintomas como dor de cabeça e dor de barriga representam mais de 50\% da amostra total. Dor de cabeça foi o sintoma mais citados pelos moradores com diferentes espécies indicadas para o tratamento, possivelmente por ser um sintoma muito recorrente na comunidade.

Dentre as partes vegetais mais utilizadas, a casca entra na composição da metade das receitas documentadas, seguida da folha, semente, óleo, assim como a estrutura do cipó. Em geral, no caso das arvores amazônicas, as cascas são mais facilmente acessadas (COELHO; FERREIRA, 2009; LIMA et al, 2014).

A espécie Hymenaea courbaril (Jatobá) possui ótimas propriedades tecnológicas da madeira, pois é dura ao corte, apresenta média resistência ao ataque de agentes xilófagos sob condições naturais e é recomendada na construção naval e na construção civil (GONZAGA, 2006). Também é utilizada na medicina alternativa com o uso da casca para produção de chá. De acordo com Shanley e Medina (2005), a seiva também é usada como remédio, pois quando exposta ao ar, forma uma resina, conhecida como jutaicica, normalmente, encontrada na base do tronco, esta é utilizada para alívio de dor de estômago, e é queimada para inalação em casos de resfriados.

O reconhecimento do valor biológico e a utilização múltipla de espécies florestais podem contribuir para a conservação e utilização mais consciente dos produtos de origem florestal, influenciando assim a dinâmica da flora e fauna (AYRES \& BEST, 1979). Além disso, informações sobre a cultura terapêutica indígena podem auxiliar a preservação do conhecimento indígena, bem como em estudos fotoquímicos e farmacológicos (ROCHA \& MARISCO, 2016).

\section{Conclusões}


Foram identificadas noves espécies florestais com interesse medicinal para os indígenas, que estão divididas em quatro famílias botânicas, entretanto duas espécies não foram identificadas. As espécies florestais são utilizadas de maneira medicinal por indígenas e comunidades tradicionais. Esse conhecimento empírico, juntamente com a prática, é repassado de geração em geração. Diante dos resultados, nota-se que as plantas medicinais possuem uma importância na aplicabilidade terapêutica, mas também é possível observar o impacto cultural desses produtos nas comunidades.

\section{Referências}

ASSOCIAÇÃO BRASILEIRA DAS EMPRESAS DO SETOR FITOTERÁPICO, SUPLEMENTO ALIMENTAR E DE PROMOÇÃO DA SAÚDE. ABIFISA. Disponível em: <http://www.abifisa.org.br/noticias>. Acesso em: 14 de Setembro de 2018.

AYRES, JM; BEST, R. Estratégias para a conservação da fauna amazônica. Acta amazônica, v. 9, n. 4, p. 81-101, 1979.

BADKE, M.S. Conhecimento popular sobre o uso de plantas medicinais e o cuidado de enfermagem. (Dissertação de Mestrado). Pós-graduação em enfermagem, Centro de Ciências da Saúde, Universidade Federal de Santa Maria. Santa Maria, RS, Brasil. 92 p. 2008.

BORRÁS, M.R.L. Plantas da Amazônia:medicinais ou mágicas - Plantas comercializadas no Mercado Municipal Adolpho Lisboa. Manaus: Editora Valer, Governo do Estado do Amazonas. 322p. 2003.

BRASIL, Ministério da Saúde. Secretaria de Ciência, Tecnologia e Insumos Estratégicos. Departamento de Assistência Farmacêutica. Política Nacional de Plantas Medicinais e Fitoterápicos. Brasília: Ministério da Saúde, 2006b.

BRASILEIRO, B.G.; PIZZIOLO, V.R.; MATOS, D.S.; GERMANO, A.M.; JAMAL, C.M. Plantas medicinais utilizadas pela população atendida no "Programa de Saúde da Família", Governador Valadares, MG, Brasil. Revista Brasileira de Ciências Farmacêuticas, v. 44, n. 4, 2008.

CARDOSO, D.; et al.. Amazon plant diversity revealed by a taxonomically verified species list. Proceedings of the National Academy of Sciences of the United States of America, v. 114, n. 40, p. 10695-10700, 2017.

CASTRO, C.V. A proteção do conhecimento tradicional dos povos indígenas sob a concepção do pluralismo jurídico. Universidade Federal de Santa Catarina, 2007.

COELHO-FERREIRA, M. Medicinal knowledge and plant utilization in an Amazonian coastal community of Marudá, Pará State (Brazil). Journal of Ethnopharmacology, n. 126, p.159-175, 2009. 
DA SILVA PEREIRA, Maria das Graças; COELHO-FERREIRA, Márlia. Uso e diversidade de plantas medicinais em uma comunidade quilombola na Amazônia Oriental, Abaetetuba, Pará. Biota Amazônia (Biote Amazonie, Biota Amazonia, Amazonian Biota), v. 7, n. 3, p. 57-68, 2017.

DI STASI, Luiz Claudio. Plantas medicinais verdades e mentiras: o que os usuários e os profissionais de saúde precisam saber. UNESP, 2007.

GONZAGA, A. L. Madeira: uso e conservação. Brasília: IPHAN/MONUMENTA, 246 p. 2006.

JUDD, W. S., CAMPBELL, C. S., KELLOGG, E. A., STEVENS, P. F., DONOGHUE, M. J. Sistemática Vegetal: um enfoque filogenético. 3. ed. Porto Alegre: Artmed, 612p, 2009.

LIMA, P. G.; COELHO-FERREIRA, M.; SANTOS, R. S. A floresta na feira: plantas medicinais do município de Itaituba, Pará, Brasil. Fragmentos de cultura. Goiânia. v. 24, n. 2, p. 285-301, 2014

ROCHA, R.; MARISCO, G. Estudos Etnobotânicos em Comunidades Indígenas no Brasil. Revista Fitos, Rio de Janeiro, Vol, 10(2), 95-219, Abr-Jun 2016.

NOLLA, D.; SEVERO, B.M.A.; MIGOTT, A.M.B.M. Plantas Medicinais. 2 ed. Passo Fundo: UPF, 2005.

RODRIGUES, E. Plants and Animals Utilized as Medicines in the Jaú National Park (JNP), Brazilian Amazon. Phytotherapy. n. 20, p. 378-391, 2006.

SHANLEY, P.; MEDINA, G. Frutíferas e plantas úteis na vida amazônica. Belém: CIFOR, 300 p. 2005.

SIASI/SESAI. Dados Populacionais de 2010 das Etnias Indígenas Cadastradas no Siasi DSEI. Página da Secretaria de Saúde Indígena. Consultada em 13 de Agosto de 2018. Disponível em: <http://portalms.saude.gov.br/saude-indigena/gestao/siasi>

SIMÕES, C. M. O.; MENTZ, L. A.; SCHENKEL, E. P.; NICOLAU, M.; BETTEGA, JR. Plantas da Medicina Popular do Rio Grande do Sul. 5. ed. Porto Alegre: Editora da UFRGS, v.1. 150 p, 1998.

VÁSQUEZ, S. P. F. MENDONÇA, M. S. NODA, S. N. Etnobotânica de plantas medicinais em comunidades ribeirinhas do Município de Manacapuru, Amazonas, Brasil. Acta Amazônica. v. 44, n. 4, p.457-472, 2014.

VEIGA JUNIOR, V.F., PINTO, A.C., MACIEL, M.A.M. Plantas medicinais: Cura segura? Química Nova 2, no 3, p: 519-528, 2005.

VIEGAS JUNIOR, C., BOLZANI, V.S.,BARREIRO, E.J. Os produtos natuais e a química modena. Química Nova, V. 29, nº 2. pag 326-337, 2006. 